\title{
How Framing Effect Impact on Decision Making on Internet Shopping
}

\author{
Xiaoying Li, Wenquan Ling \\ Management Institute, Jinan University, Guangzhou, China \\ Email: 175268520@qq.com, tlwq@jnu.edu.cn
}

Received 27 December 2014; accepted 17 January 2015; published 20 January 2015

Copyright (C) 2015 by authors and Scientific Research Publishing Inc.

This work is licensed under the Creative Commons Attribution International License (CC BY). http://creativecommons. org/licenses/by/4.0/

(c) (i) Open Access

\begin{abstract}
Framing effect is an understanding and assessment that individual implements different behaviors when facing to the multiple choice that expressing the same meaning. Previously, scholars went through numerous empirical studies regarding impact of the method as well as environment in making decision of online purchasing [1]-[4]. Also, scholars have proved that there are complex influences of psychological factors when consumers make decisions of shopping. Therefore, the article aims to analyze the impact of faming effect in e-commerce when consumers make decisions so as to summarize the shortage in academic and practical aspects.
\end{abstract}

\section{Keywords}

Framing Effect, Online Shopping, Making Decision, E-Commerce

\section{Introduction}

Nowadays, online shopping has become the trend of consuming model. According to the report announced by Chinese Online Shopping Marketing Analysis in 2012, the number of transaction in online consuming market reached approximately one thousand two hundred billion yuan (RMB) in 2012, increasing by 66.5 percent than in 2011. In 2012, the rate of transaction in online retail took up 6.1 percent among social retails. In this case, the data from online shopping in China is drawn attention to scholar for research about consumer behavior in making decision, which drives the development of E-commerce.

Consumers constantly confront the situation that when you intend to buy a shampoo in one online store where provides the free-delivering service if paying 45 yuan RMB, another store, on the contrary, charges 55 yuan RMB for the same product including price of product (45 yuan RMB) and cost of delivering (10 yuan RMB). In this case, which store will you choose? What's more, when we see the slogan on the website from an online store where signs that those who find out the fake product could get the compensation with ten times of the retail 
price; similarly, another store insists that no fake for sale because the store is qualified by the brand, how do we make a decision?

The situations we described above are belonging to the different recognition, value perception and decisionmaking under the same information with the different expression. The significant difference between online consuming and physical consuming is that most of consumers purchase products on the internet before searching information of products that provided by the website in the uncertain or potentially risky environment, while shopping in the physical store runs the opposite. Hence, how we can make decisions rationally is a hotspot in academic of framing effect.

As for the novelty of the study is on one thing that we suppose there is a relationship between online shopping and diversity of framing effect because most of the previous researches have proved that in different occasion traditional consuming decision will be influenced by the framing effect. However, the research did not involve more detail in whether there are different impacts on shopping behavior on the internet or decision-making in ecommercial environment as a result of different conditions and decisional environment in online shopping, which doesn't have the same factors as traditional consumption. Similarly, the previous researches have proved experimentally that different environments and conditions would have different impacts on purchase decisions so that it forces us to believe that framing effect integrated by e-commercial situation would bring the another effect on decisions of consumption and behaviors. On the other things, in terms of the category of precise consuming behavior and decision behavior, there is no relevant research made on these before. As for the consequence of purchase, it is related to various aspects (i.e., whether to purchase, the quantity of product, the types of product).

\section{Definition, Origin and Category of Framing Effect}

\subsection{Definition and Origin of Framing Effect}

Before the theory of framing effect, scholars presented the Expected Utility theory demonstrating that in uncertain and potentially risky situation, individuals estimate the potential consequence before making decisions. The theory dominated the crucial place in risky decision until 1944; Von Neumann and Morgenstern [5] carried out a new utility model according to this theory and supposed that human preferred to make decisions to match the highest expectation.

However, not all the people could exhibit rational behavior in our daily life because of the limited knowledge. Individuals are not competent to make perfect in decision with rational principle during the period that people lack of knowledge and unforeseen risks. That is the reason why decision-making could not stand in line with Expected Utility Theory, which stimulates psychologists and economists to research the related theory about decision-making.

Framing effect is origin from the problem of Asian disease that Kahneman and Tversky studied [6]. They got ready for preventing from extremely terrible disease which was coming and anticipated 600 people would lose lives in this disaster. Therefore, they showed us two expressions of plans about the solution.

A classic example of framing effect is Tversky and Kahneman's [6] Asian disease problem. In their study, the projects were required to select between a confirmed consequence that led to a certain survival of one third of 600 hypothetical patients (200 people) and a risky probabilistic consequence, a one-third probability that all 600 people would survive and a two-thirds probability that no one would survive.

In contrast, the projects described as loss were required to select between a certain consequence that led to a certain death of two thirds of 600 hypothetical patients (400 people) and risky probabilistic result, a one-third possibility that no one would die and a two-thirds possibility that 600 people would lose their lives.

As a result, most of their subjects (72\%) favored the certain thing when the choice results were framed in terms of lives saved whereas most of the subjects (78\%)in another group favored the gamble (the possibility) when the same choice outcomes were framed in terms of lives lost. We could find out that these problems expressed the same meaning. The unique distinctness was the key word in beneficial environment was described a survival, another group was the death.

Accordingly, people code the possible choice outcomes as gains and losses, and tend to be risk averse when choosing among prospects seen as gains but risk seeking when choice selections were framed positively, people are fancy to recognize them as gain and become more risk averse. On the contrary, when the same selections are framed negatively, people are more likely to foresee them as lost and become more risk finding. There is no 
doubt that Tversky's theory makes a contribution to framing effect analysis and our essay.

\subsection{Category of Framing Effect}

With development of theory of framing effect, scholars expand the research of various phenomena, and the technological innovation develops numerous new situations, which arouse awareness of psychologists and economists. For these reasons, framing effect should have a clear category.

\subsubsection{Bidirectional and Unidirectional Framing Effects}

X.T. Wang [7] found out dynamic and mechanism of framing effect in terms of risky choice of death, public property and individual benefit. As a result, there are two types framing effects defined with theory and empirical recognition, namely bidirectional framing effect and unidirectional framing effect.

Bidirectional framing effect, a traditional framing effect, drives to change risk preference when positive framing choices are transferred to negative framing choices. Faming Hou designed the experiment to demonstrate that in terms of personal property, individual tended to risk averse while the one who stayed in the negative framing effect focus on risk seeking.

However, there is no preference change under unidirectional framing effect. In fact, when the hypothetical patients were described as subjects' own family members, the subjects, although clearly being risk seeking, become extremely more risk seeking if the choice consequence was framed negatively.

\subsubsection{Risky Framing Effect, Attribute Framing Effect \& Action Framing Effect}

Risky framing effect, the most typical explanation, is used for highest times in framing research. F.M. Hou [8] preceded the experiment that how post-graduate students and employed people made risky decision in terms of life, money and personal things. At last, he found out that there were extremely different preferences of making decision under the framing effect.

Attribute framing effect will infulence individuals encoding and assessment of the object or characteristics. F.M. Xu [9] summarized the traits of attribute framing effect including: 1) no risk; 2) distinctive; 3) no preference change by comparing with other types of framing effects. As a common phenomenon in economics, Xu concluded the previous explanation of attribute framing effect from other researchers, addressed the perspective and explored widely regarding the origin, factors of impact, application, the relationship with other decisions. In addition, this framing effect is applied in consuming domain constantly so that the contribution of research could bring huge impact on consuming decision.

C.J. Liang and X.R. Li [10] deemed that action framing effect was a behavioral purpose that individuals wanted to achieve one certain goal and a behavioral consequence related to one certain goal. The positive and negative action framing effect is the relationship between the individual and goal achievement. An experiment, designed by C.J. Liang and X.R. Li, illustrated that positive action framing effect intensified the impulsive behavior of consumer who is directional. Since the appearance of action framing effect, researchers struggled to study mechanism and factor of that to understand the origin and performance so that company could set up an effective strategy to persuade consumer to take action and prevent negative effect.

\subsection{Theoretical Interpretation of Framing Effect}

\subsubsection{Prospect Theory}

Prospect theory, was put forward by Kahneman and Tversky in 1979, is the first theoretical explanation of framing effect, which reveals the people who would not complement completely rational action always prefer to deviate rationality. The theory of the individuals in decision-making can be divided into two stages, editing and evaluation. Kahneman and Tversky argued that, in the editing stage, individual decision makers mainly through coding, combination, decomposition, reducing or other related processes methods, integrated information; meanwhile, in the evaluation stage, according to the value function and weight function the individual decision makers selected different options of utility value [6].

In prospect theory, the reference point is an important criterion of evaluation when making decision [6]. Choosing what kind of reference point is the vital role in changing and manipulating people's decisions. What's more, the value function is to coordinate the reference point as the center, presenting an s-shaped curve. Loss area presents the convex curve and decreases rapidly resulting in that people are more sensitive, while yield area 
appears concave curve. That explains the reason why under framing effect, when making decision, individuals facing with a positive, active benefit, tend to avoid risk as opposite as the negative, more people tend to seek risk. Comparing to the pain from lost, the joy of the equivalent gain is more strong, namely loss aversion [11].

With the development of research, scholars have found that there are drawbacks in prospect theory that cannot fully explain the framing effect. First, the reference point and the value function is difficult to measured and estimated; second, the differences of the individual decision-making cannot be reflected in the prospect theory. In order to solve these problems, scholars turned to consider cognitive theory where the fuzzy-trace theory hit the world.

\subsubsection{Fuzzy Theory}

Fuzzy theory was created by Reyna (1991), used to interpret the traditional framing effect [12]. The principle of theory is to prefer to operate to reason informational instinctive gist rather than a logical way. Also, theory proved that the advanced judgment and decision-making was based on a simple, selective gist of mental representation (fuzzy memory trace) rather than a more specific, quantitative digital representation (literal memory trace). Trace, a single meaning extracted from the information (semantic representation), is related to the personal knowledge, understanding, culture and development level [13]-[16]. Because in the field of personal development and the need for more professional knowledge, their decisions would tend to be based on the meaning of information, rather than the details of verbatim [17].

Nowadays, scholars attempt to apply actually to practice with the theory. They deem that people are parallel and independent to extract essence trace and literal trace information, prefer to trace information and make judgments based on the information [18]. The expression of fuzzy effect of tax revenue can promote the development of the market. Individual preferences exist fuzzy processing but there is no linear relationship between the objective digital results and individual subjective perception of its. In that case, bonus will become the extra income for individual in our mind; in addition, the overall wealth will be rising as a cognitive. On the contrary, no one focus on the digital information which impacts our preference in decision-making by the description of the fuzzy model [19]. J.W. Duan [20], by means of empirical experiment in terms of market competition and starting business defined as two risky choices, proved that the influence by fuzzy theory in market competition situation outweighed the counterpart of entrepreneurship, and the former has a significant level, the latter run the opposite which to verify that under circumstance of the entrepreneurial risk, most people in the judgment of characterization of digital information roughly estimate fuzzy information, and the fuzzy representation has significant impact on the final choice.

Indeed, the fuzzy theory in terms of memory, reasoning, intuition and other related cognitive factors interpreted the decision-making behavior, but because gist of trace is complicated to be measured and a strong fuzzy cognitive causes different interference, therefore scholars put forward another theory called "equate-to-differentiate theory".

\subsubsection{Equate-to-Differentiate Theory}

The theory, presented by Chinese scholars [21]-[24] was based upon limited rational point of view [25]. As the content of the theory, living in risky and uncertain circumstances, human being does not tend to match the maximum expectation in decision-making, but choose upon identifying one form whether there are advantages and disadvantages. The significantly difference compared with Expected Utility theory is equate-to-differentiate theory denies decision preference that is to achieve maximum expectation. The specific process is divided into two parts, equate and differentiate. Decision maker will equate the less different result on one dimension and define the extremely different dimensions as top priority of options. This is the perfect example that making decisions by means of the principle of "weaken advantage”.

Equate-to-differentiate model illustrated and explained the classic framing effect, since the framework of the subjective option can be described in two dimensions containing best possible outcome and worst possible outcome. Human beings with lower cognitive ability consider that the results are subjective or equal, leaving another single dimension be regarded the difference of options. The process of "equate” can let decision makers have lower cognitive ability. In the "differentiate” stage, if the decisive dimension is one of the best possible results, individuals tend to pursue the best goal during this period, or if the definitive dimension is the worst possible result, then the decision make us avoid the worst possible target. 


\section{Decision of Consumer on Online Shopping}

\subsection{The Concept}

Every day each person has to make numerous decisions with all aspects of daily life. Broadly speaking, decision-making is to select the best one from two or more choices and the choice must be feasible as well. Actually, buying decision is a part of the consumer behavior [26]. Some scholars believe that decision-making of consumer is the purchasing intention, reflecting the psychological mechanism of consumption decisions. Therefore, this article upon the background of network consumption decisions, compared the traditional consumption mode, researches new consumption patterns of consumer's decision-making behavior on internet environment.

Some researches focused on consumer's decision-making process on network. Simon thought that the process of shopping decision-making was divided into the following steps: cognition, design and choice [25]. Additionally, buying decision, defined by AMA (the association of American market) and based on switching, contains perception, emotion, cognition, behavior and the interaction between environmental factors. Haubl and Trifts believe that potential consumers seem to utilize two steps to reach the decision [27]. The first is to identify the possibility of choice to obtain the demand by means of scanning a large number of products. The second is to precede evaluation of the choice above in deep way and compare according to specific reason and consumer decision-making. S. Chen supposes that consumers purchasing decision refers to the process of purchase [28]. In other words, the consumer achieves the certain requirements with information searching, seeking solutions, choosing and determining the optimal process, post-purchase evaluation and a series of activities. C.S. Wu and F.F. Cheng believed that consumers purchase decision is mainly made up of three parts, including purchase intentions, purchase attitude and willingness to pay [29].

To sum up, the emphasis of the different scholars of understanding consumers' network decision-making is multifarious, but the essence of decision-making described by scholars has a consistency, namely meeting the needs of consumers. Hence, in this paper, the concept of a purchase decision is defined that consumers meet their own needs somehow, through the network media to make decisions mainly including the purchase intentions, purchase attitude and willingness to pay.

\subsection{Purchasing Decision Model}

\subsubsection{Nicosia Model}

Nicosia Model was put forward in 1966, as the core content of the book called Process of Consumers' purchase. There are four areas simulated by Nicosia. Phase 1 is a procedure from information releasing to consumer attitudes. In that procedure, the enterprise through the dissemination channels pass relevant brand's contents to consumers, this information will be treated with consumers to form a specific attitude towards a product. Phase 2 is called evaluation. After the consumers receive information from dissemination, they will form a certain attitude of brand in their mind. After that, consumers search the relevant information of the product with this certain attitude and estimate the content of the information for its corporate communications and product to trigger purchase motivation. Phase 3 is called purchasing behavior that the driving of the consumers' motivation in consumer decision and the specific purchase behavior. Phase 4 is called feedback that shape the experience as the memory in the brain, which guide future consumption, after consumption of experience or product and that feedback to enterprise from the consumption experience of consumers. As shown in Figure 1.

Nicosia Model concisely induces the consumer decision-making process, but the process does not illustrate the impact on external factors and ignores the situation that the interaction and communication between consumers and enterprises are multitudinous.

\subsubsection{Howard-Sheth Model}

This model was put forward by Howard and Sheth together in 1977, enriched the consumer decision-making process and classified into four categories: input variety, cognitive structure, the structure of the study, output results. The input variety is stimulus or input including three factors: product essential factor (i.e., quality, price, features, service, and utility); the symbolic factor (i.e., medium as the transmission of information constitute); social environmental factor which is the external environment for product information transferring stimuli (i.e., family, related groups and the social hierarchy). Cognitive and learning structures describe that after stimulated 


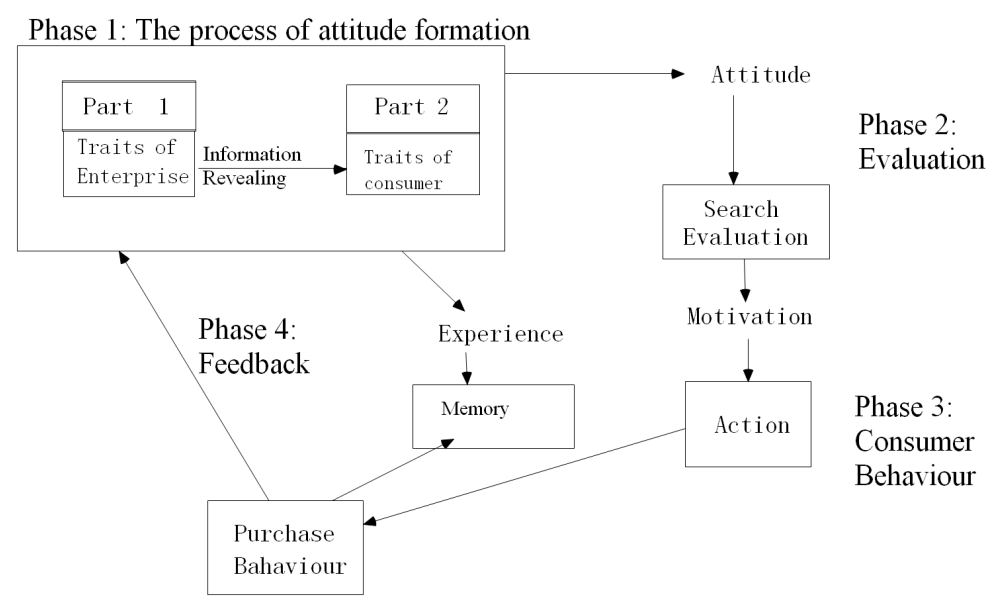

Figure 1. Nicosia model.

by external factors, consumer trigger a series of changes in psychological activity and the psychological process of the purchase decision. Cognitive structure includes the public search, fuzzy knowledge and attitude of stimuli and preferences of perception, While learning structure between consumer decision-making and external stimuli contains the criteria of selection, the brand understanding, attitude, trust, motivation, satisfaction, intention, reflecting the process of processing and forming a attitude toward products in our brain as a vital procedure of making purchasing decision after accepting external stimuli. Finally, the output results, reflecting that the consumer finally trigger a product purchasing behavior, contains three meanings. First, the attention of consumers about a product and the understanding of the brand; second, emotional response related to the learning structure; third, interacting behavioral responses whether decided to implement a specific behavior. Exactly as shown in Figure 2.

The description of Howard and Sheth model are logical and practical, especially suitable for consumers of various products brand choice and purchase [30]. But the consumer decision-making process is embedded in a particular social system or deciding correlative system, therefore, the study overlooked the consumer decisionmaking in the correlative system between each other [31].

\subsubsection{EBM Model}

EKB model is put forward by Engel, Blackwell and Kollat as a systematic and comprehensive model of decision-making in 1968 [32]. The core content of model is to distill systematically each variety and the relationship among them from the consumer decision-making process. In order to make the EKB model more effective description of consumer behavior, so Englel, Blackwell and Miniard revised the content of EKB model and turned out a new model that was called EBM model, which became a kind of explanatory model and was divided into four parts: 1) the central control system, namely process of the consumer psychological activity; 2) part of informational process; 3) the decision-making process; 4) environment. They believed that external stimulating factor would stimulate the brain cortex to filter pro- cessing information. Stimulating factors mainly include commodities, the mass media and enterprises promotion, etc., through the central control system—visual, hearing, feeling and memory, and standard of consumption would be integrated, so as to know the goods and make a comprehensive assessment and selection, eventually become the decision result. At the same time, environmental factors which are also defined as economic, political, cultural and social factors can affect the decision-making process as well. Consumers after decision-making began to implement specific and concrete consumption behavior and evaluate the product after purchase use and consumption experience to feedback to the central control system, which became the influence factors of consumer spending decisions in the future. As shown in Figure 3.

\subsubsection{Kotler Stimulus-Response Model (Kotler Model)}

Kotler stimulus-response model was presented by Kotler (1995) with the perspective of psychology and systematic analysis on the consumer's decision-making behavior as well as combining the general pattern of human behavior, also called "S-O-R" model [33]. S for stimulate, $\mathrm{O}$ for organisms and $\mathrm{R}$ for response. Part $\mathrm{S}$ is a stimulus that arouse 


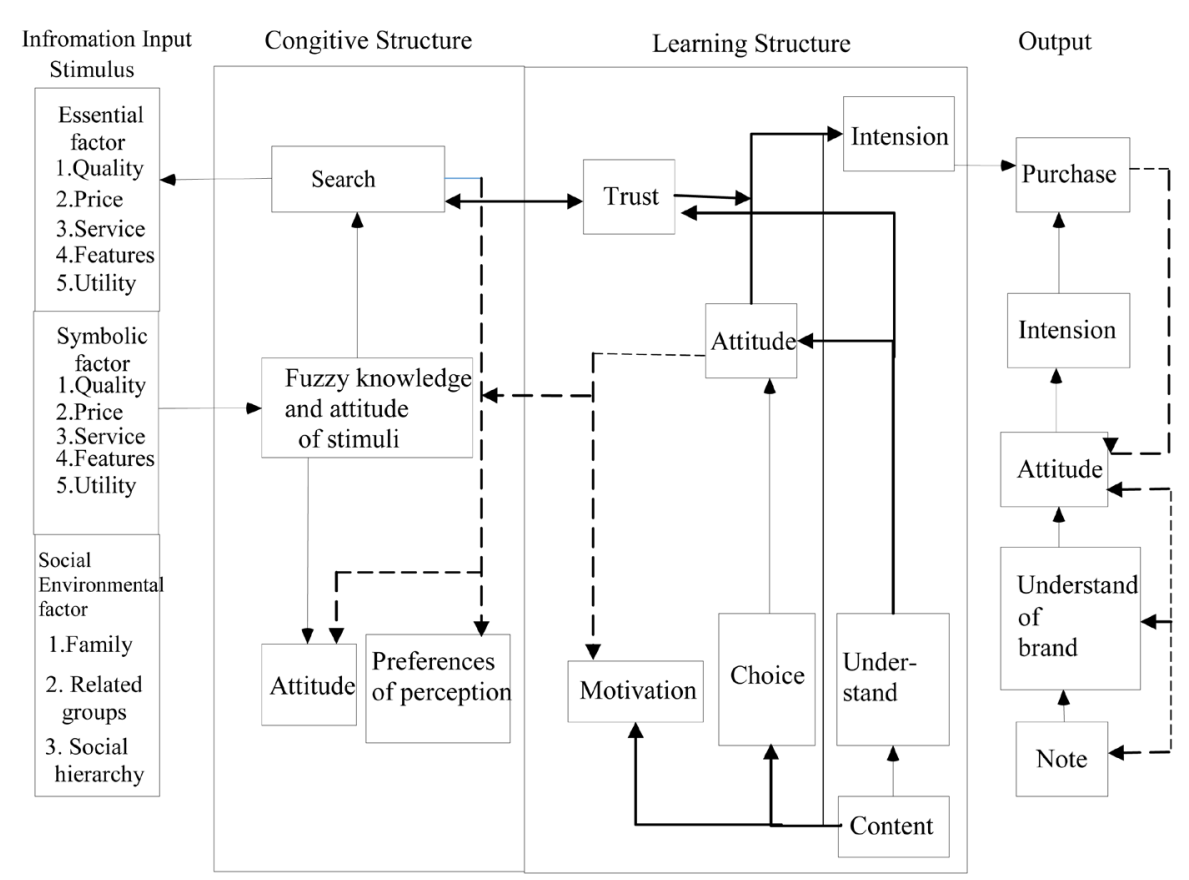

Figure 2. Howard-Sheth model.

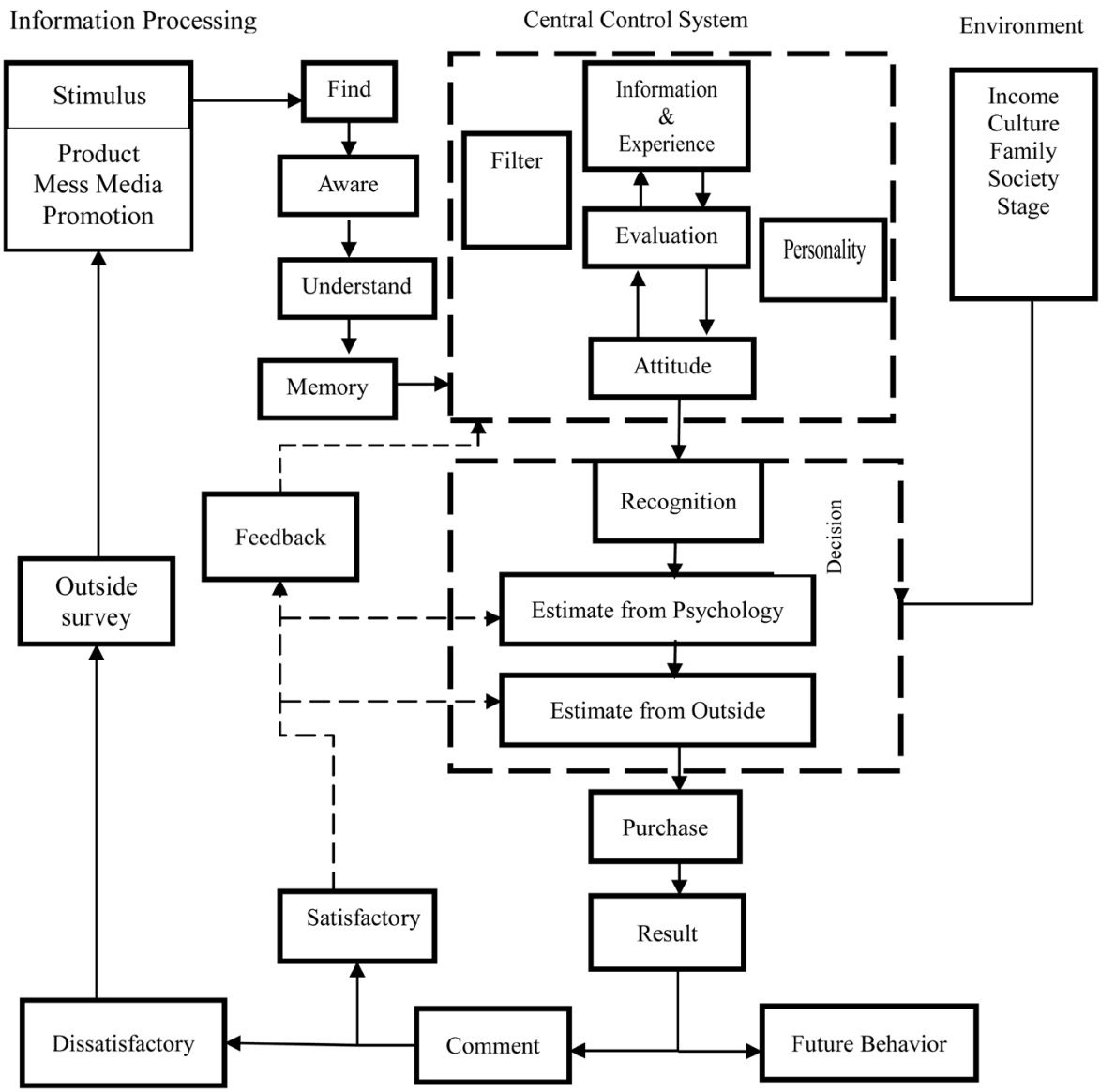

Figure 3. EKB mode. 
the attention of consumers, including external stimulus (i.e., product, price, channel and promotion) and environmental stimuli (i.e., economy, politics, culture, science). Part $\mathrm{O}$ is called "Black Box", representing the consumer's psychology, mainly including the characteristics of consumers (i.e., social, individual, psychological and cultural) and the consumer decision-making process (i.e., problem recognition, information searching, standards, assessment and purchase behavior). Meanwhile this part, which plays an essential role in the consumer behavior, brings an important impact on consumer behavior. Whereas Part R is the concrete consumer's decision-making behavior (i.e., commodity choice, the choice of suppliers, brand choice and purchase quantity). As shown in Figure 4.

The shortcoming of the model is that it neglects brain processes after accepting information and over emphasizes on "black box", namely the characteristics of consumers and the consumer psychological activity influence on consumer decision-making.

\subsubsection{Model of Consumer Decision-Making on Network}

Decisions between consumption on network and consumption in traditional way have many similarities. Different scholars analyzed network consumption and generalized the corresponding model according to the traditional consuming decisions. Q. Ke [34], who searched from Kotler model and combined the feature of network consumer behavior (individuation, rationalization, initiative), built up pattern of the network consumers' purchasing behavior. As shown in Figure 5.

S.S. Li [35] combined Nicosia and Howard-Sheth model with the characteristics of online consumer to put forward the integration of the traditional shopping model, online information searching and offline consumption and online consumption of the comprehensive model. The model is added the way of purchasing into the scope of the consumer decision-making to which is needed to consider and makes up the shortage of traditional and online shopping decision model when considering decisions. What's more, the model is based on limited type of consumers and dilated consumers. Limited type of consumers are characterized by medium intervention, limited information searching, simple rules, limited backup solution, while dilated consumer runs opposite side [36]. As shown in Figure 6.

With the development of e-commerce and information technology, consumer spending patterns will become diverse, and factors which influence behaviors of shopping will also increase, because the consumer decisionmaking model also needs to be integrated into numerous comprehensive factors, but the main process is inseparable from the general decision model. To be honest, the environment of e-commerce is complex, consumer demand and behavior must be analyzed constantly so that we can fully understand the consumer's decisionmaking behavior.

\section{Related Research about Relationship between Framing Effect and Consumer Decision-Making}

Currently, application of framing effect obtained certain achievements in terms of investment, management, professional, tourism, insurance, etc. All of them have the empirical research. In recent years, the studies of the framing effect that was applied in consumer decision-making behaviors are also gradually got attention [37] [38]. But the framing effect in the field of consumption decisions did less, especially in the network of consumer decision-making.

Levin [39], C.L. Liang [10] and others combined with the framing effect and utilized beef products and digital camera as two subjects to research empirically intension and impulse buying decisions of college students. The results showed that under the risky framing effect, subjects tended to select the products with the description of the loss. On the other hand, under attributed framing effect, most of subjects favor the positive description. In the action framing effect, Levin and others showed that the framework didn't impact on the decision and there was no action framing effect. However, the result gone through by the experiment of C.L. Liang was just opposite.

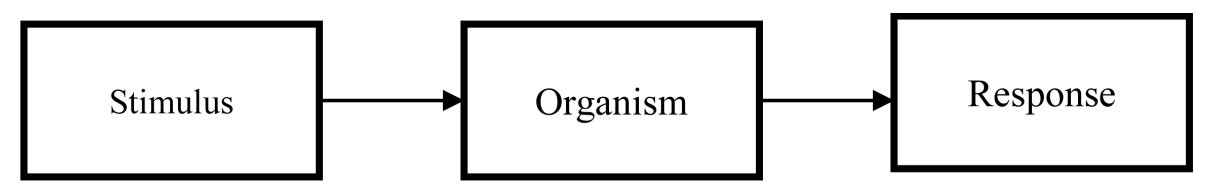

Figure 4. Kotler model. 


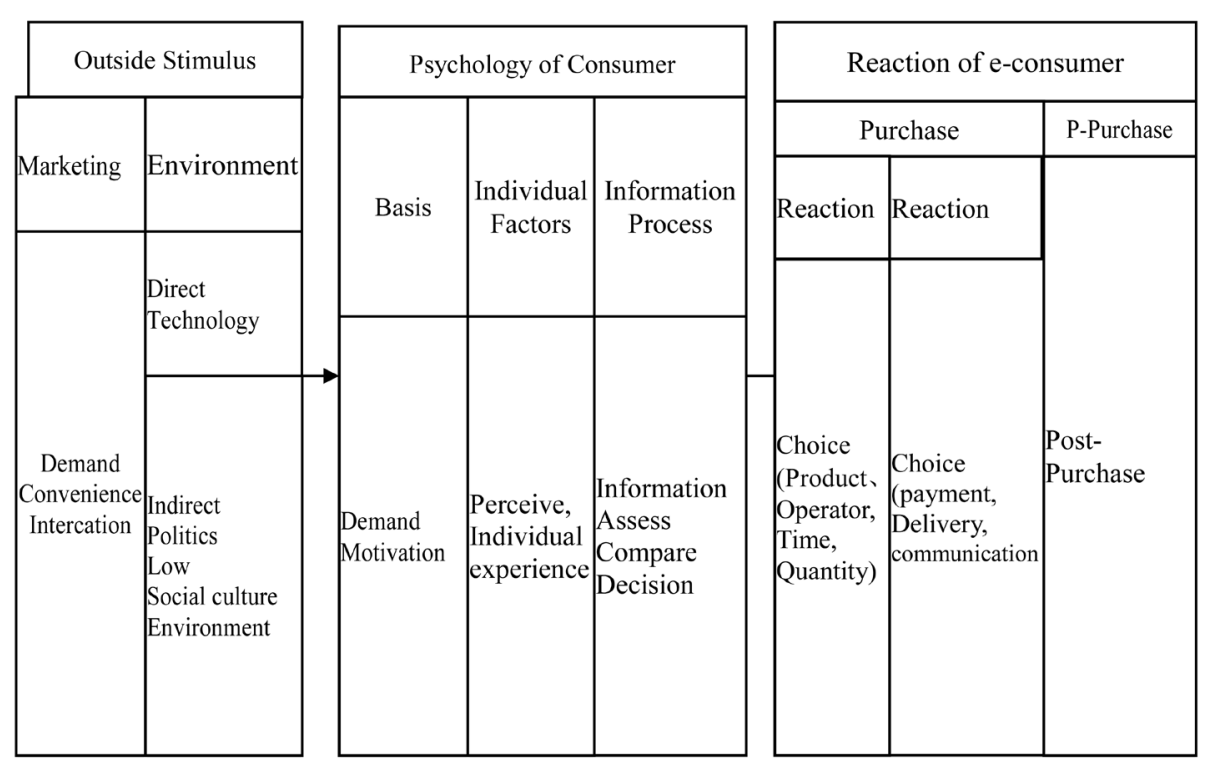

Figure 5. Network shopping decision model.

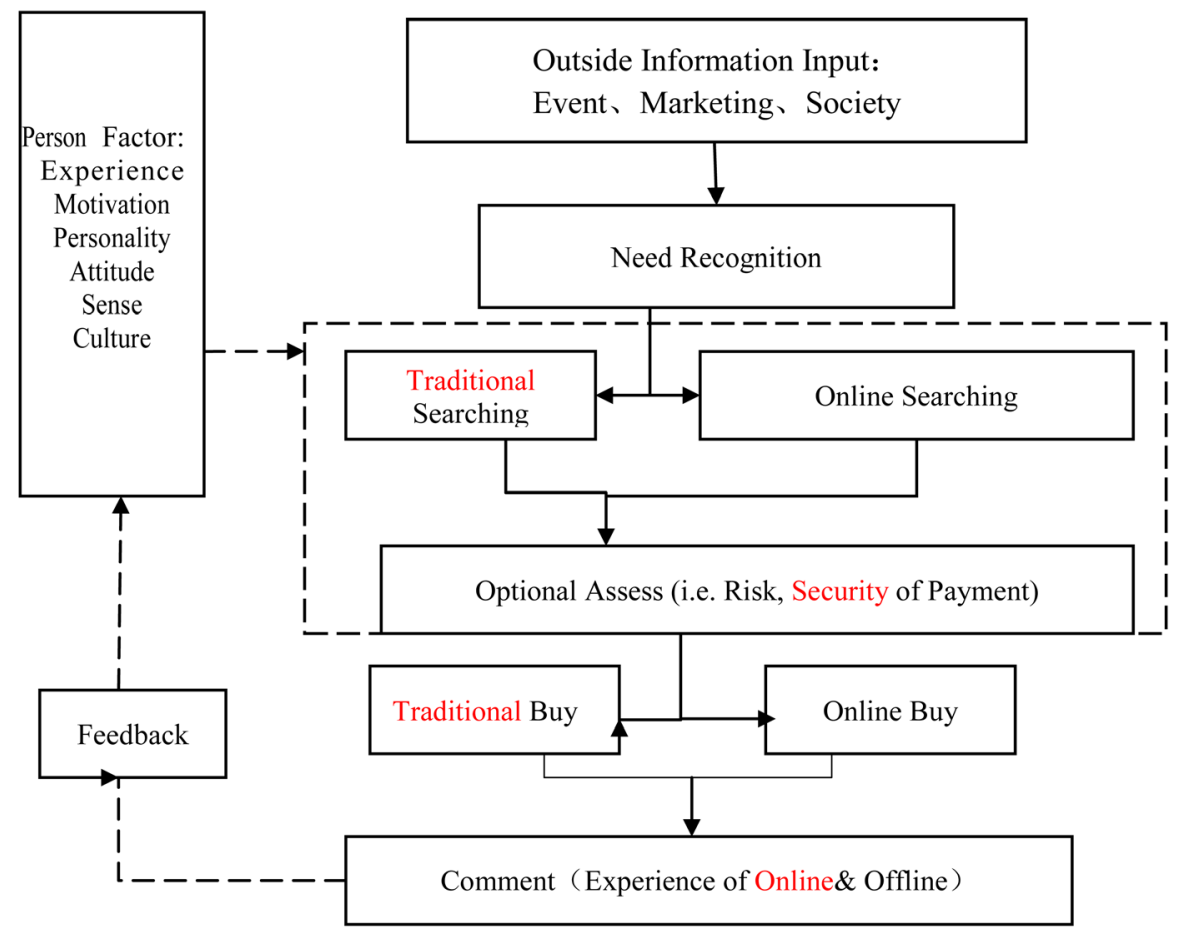

Figure 6. Integrated network shopping decision model.

In addition, the frame will affect consumer perception of price. Bingbing Mou and their partners designed the questionnaire and experiment to prove how the cognitive closure need and promotion strategies presented versus discount impact 240 college students in fuzzy consuming decision [40]. On one hand, the author thinks that with the high cognitive closure in circumstances of fuzzy purchasing, consumer decide what they want to bur without too much hesitation but being more vulnerable to "promotional informational framework". On the other hand, the influence of low cognitive closure runs an opposite trend. There is nothing different reaction between discounts and gifts.

S.L. Li and her partners [41] made an empirical analysis of the relationship between price framework in the 
bundling and consumer preferences from the perspective of product attributes. They found that when a pleasure and a firm supplies were bundled, price discount embodied in hedonic products had less expected guilt and high purchase intention than those of the real products which save money. Hence, expected guilty is the intermediary role between price framing effect and consumers' purchase intentions.

Schindler and his teammates [42] focused on how the process of sales promotion information effect influences customers when buying a car. The results revealed that consumers were not willing to remove the stuff from car that did not operate as a function, comparing to add functionality. The reason was that the function removed from the car was regarded as a lost, while adding a new function was viewed as a benefit.

The scene experimental method of Y.R. Cheng [43] was adopted. Under conjunction with the framing theory and cognitive theory, Cheng introduced how attribute framing effect, action framing effect, cognitive needs and the integration among three factors influence on college students' consumption decisions. The results illustrated that attribute framing effect and cognitive needs had a significant influence on college students purchase intentions, attitude and the way of payment. Initially, intention, attitude of target products and payment of college students who are low cognitive need are significantly higher than counterpart of university students with high cognitive need. In addition, when students, with the low level of cognitive needs and who was influenced by the framework of positive characteristics, have the higher level of purchase intention than university students that impacted by the negative description for target product. On the contrary, there is no obvious effect on purchasing intentions, attitudes and way of payment under both description of framing effect. Finally, the action framework would bring no impact on college students' consumption intention, attitude and payment.

\section{Shortages and Prospects}

\subsection{The Shortage of Current Research}

On one hand, compared with characteristic of traditional consumption, the network consumer behavior has new trait, namely the consumers cannot let consumer directly contact with the goods what they want, which is regarded as a highly complex shopping environment. On the other hand, the platform of internet offers a high information exchange environment. In other words, consumers who shop online interact with machines constantly where the web pages are exhibited by the complicated content. Not only do they have to make a based decision of online shopping, but also make a decision of the purpose, brand, channel, payment, time and quantity.

The development of the Internet, reaching the peak of information transfer, provides people with a bigger platform to communicate with each other, interact with each other, but no matter how enormous the consumption environment change, study in traditional purchase or online purchase is related to the characteristics of today's consumers. To be honest, most of consumers are more personalized; initiative, considerate and psychological mature in terms of cutting off the cost and time than any time before. In that case, the process of network consumption contains a lot of text information as the major stimulation factors; however the influences of graphic form of information description on diversity of consumer decisions are the same. What's more, a few previous researches are related to the influence of framing effect in the field of consumption. At the same time, scholars just focused on college students' group or a particular category as subjects rather than a wide range. Hence, this kind of research could not represent the general consumers, broader target product or more comprehensive consumption environment. We need more empirical study to adapt to the development of Internet and ecommerce and emerging products in the e-commerce platform.

\subsection{The Future Research Prospects}

In the classification of the framing effect, risky framework, attributed framing $\mathrm{v}$ and action framing effect in the field of consumption lead to the different results. Risk framework can influence consumer about the related risky decision (e.g., the channels of consuming, way of payment). And in attributed framing effect, positive characteristics framework is the key attributes of goal and the event which symbolize the information that make decision makers are comfortable and satisfactory as opposed to negative framework. This frame is a kind of manifestation in terms of psychology of consumer, which affect the consumer's intention, purchase attitude, willingness to pay and other psychological mood; But in action framing effect, positive action framework is that if consumers who choose this option will have a particular interest or benefit, otherwise, they will suffer from economic, healthy, experiential or others loss, which is defined as negative action framework.

Above all, the authors have several important key points for the future research. First, in e-commerce scenario, 
is there an effect of framing effect on intangible product consumption decisions? As we know, most of intangible products are the kinds of consumption experience, such as travel services, the process of information gathering and processing is the most important part of tourist destination products and services, and now increasing number of consumers choose online consumption on tourism products and offline experiences, which forms a new consumption environment. Thus, the study of the effect of framework in the field can offer a good scientific basis to tour operators, managers who are competent to come up with product information effectively and contribute to the development of tourism.

Second, under e-commerce business environment, how new promotions in terms of price framework influence brand preferences. In current period, many e-commerce platforms (e.g., Taobao, Jingdong, Suning) deliver a new form of information of promotion that captures attention of consumers, for example, some electronic suppliers offer " 0 yuan" product (RMB), or free cost for products in a limited time. This kind of strong and positive action framework attract consumers to lock certain products with the obvious advantages compared with other brand promotion. Will the consumers put their whole mind into plundering this brand with attractive discount?

Third, living in the e-business environment, what is the effect of framework on quantity of consumption? With the convenience of logistics system, online shopping impels consumers to buy the same brand with multiple units. However, for whether there is influence on quantity of consumption, we need more empirical researches in the future, because there are different ways of promotions reveal that buy more get more benefit and they do not need to consider how heavy the product. This topic has strategic significance for the retailers and suppliers who could come up with the attractive expression of promotion to capture the market share.

Fourth, how do the combination of cognitive need and framing effect impact consumption on the internet? H.H. Liang's [44] experiment revealed that cognitive need has a significant impact on individual decisions. Additionally, results of individuals' investing decisions are influenced by decision goal and different individual factors. But the relationship between cognitive needs and framing effect and whether the combination of them will impact consumption on the internet are questioned by some scholars. We need more cases and scenes to testify.

Fifth, research has focused on decisions about the framing effect of risk framework, but little study regarding attribute framing effect and the action framing effect, especially whether there is a relationship between attribute framework and action framework, so more researches are needed.

\section{References}

[1] Colin, F.C., George, L. and Matthew, R. (2010) New Progress in Behavioral Economics. China Renmin University Express, Beijing.

[2] Del, I.H., Roger, J.B. and Kenneth, A.C. (2004) Consumer Behavior (Translator, Fu Guoqun). China Machine Press, Beijing.

[3] Jagdish, N.S. and Banwari, M. (2004) Perspective of Consumer Behavior Management (Translator, Luo Li). China Machine Press, Beijing.

[4] Leon, G.S. and Leslie, L.K. (2007) Consumer Behavior (Translator, Fu Guoqun). China Machine Press, Beijing.

[5] Von Neumann, J. and Morgenstern, O. (1994) Theory of Games and Economic Behavior. Princeton University Press, Princeton.

[6] Kahneman, D. and Tversky, A. (1979) Prospect Theory: An Analysis of Decision under Risk. Econometrica, 47, 263291. http://dx.doi.org/10.2307/1914185

[7] Wang, X.T. (1996) Framing Effects: Dynamics and Task Domains. Organizational Behavior and Human Decision Processes, 68, 145-157.

[8] Hou, F.M. (2013) The Factor of Framing Effect in Risky Decision. Capital Normal University, Beijing.

[9] Xu, F.M., Wen, G.C., Yu, H.H., Huang, B.Z. and Wang, L. (2011) The Psychological Mechanism and Influential Factor of Attribute Framing Effect. Advances in Psychological Science, 19, 1822-1833.

[10] Liang, C.L. and Li, X.R. (2012) The Effect of Framing Message on Impulse Buying Behavior. Journal of Shandong University of Finance, 1, 72-81.

[11] Liu, M. and Liu, X.W. (2008) To Review on Research of Loss Aversion under Prospect Theory. Value Engineering, 10, 143-136.

[12] Reyna, V.F. (1991) Class Inclusion, the Conjunction Fallacy, and Other Cognitive Illusions. Developmental Review, 11, 317-336. http://dx.doi.org/10.1016/0273-2297(91)90017-I 
[13] Reyna, V.R. and Brainerd, C.J. (1993) Domains of Fuzzy-Trace Theory. In: Howe, M.L. and Pasnak, R., Eds., Emerging Themes in Cognitive Development, Springer-Verlag, New York.

[14] Reyna, V.F. (2004) How People Make Decisions That Involve Risk: A Dual-Processes Approach. Current Directions in Psychological Science, 13, 60-66. http://dx.doi.org/10.1111/j.0963-7214.2004.00275.x

[15] Reyna, V.F. and Brainerd, C.J. (1998) Fuzzy-Trace Theory and False Memory: New Frontiers. Journal of Experimental Child Psychology, 71, 194-209. http://dx.doi.org/10.1006/jecp.1998.2472

[16] Reyna, V.F. and Farley, F. (2006) Risk and Rationality in Adolescent Decision Making: Implications for Theory, Practice, and Public Policy. Psychological Science in the Public Interest, 7, 1-44.

[17] Reyna, V.F. and Lloyd, F.J. (2006) Physician Decision Making and Cardiac Risk: Effects of Knowledge, Risk Perception, Risk Tolerance, and Fuzzy Processing. Journal of Experimental Psychology: Applied, 12, 179-195. http://dx.doi.org/10.1037/1076-898X.12.3.179

[18] Reyna, V.F. and Mills, B.A. (2007) Converging Evidence Supports Fuzzy-Trace Theory’s Nested Sets Hypothesis (But Not the Frequency Hypothesis). Behavioral and Brain Sciences, 30, 278-280. http://dx.doi.org/10.1017/S0140525X07001872

[19] Epley, N., Mak, D. and Idson, L.C. (2006) Bonus of Rebate: The Impact of Income Framing on Spending and Saving. Journal of Behavioral Decision Making, 19, 213-227. http://dx.doi.org/10.1002/bdm.519

[20] Duan, J.Y., Wang, Z.M. and Tian, X.M. (2013) The Study of Cognitive Theory for Framing Effect in Entrepreneurial Risky Decision-Making. Psychological Exploration, 33, 123-128.

[21] Li, S. (1994) Is There a Problem with Preference Reversals. Psychological Reports, 74, 675-679. http://dx.doi.org/10.2466/pr0.1994.74.2.675

[22] Li, S. (2001) Extended Research on Dominance Violations in Similarity Judgments: The Equate-to-Differentiate Interpretation. Korean Journal of Thinking and Problem Solving, 11, 13-38.

[23] Li, S. (2003) Violations of Conjoint Independence in Binary Choices: The Equate-to-Differentiate Interpretation. European Journal of Operational Research, 148, 65-79. http://dx.doi.org/10.1016/S0377-2217(02)00367-3

[24] Li, S. (2004) Equate-to-Differentiate Approach: An Application in Binary Choice under Uncertainty. Central European Journal of Operations Research, 12, 269-294.

[25] Simon, H.A. (1976) Administrative Behavior-A Study of Decision-Making Processes in Administrative Organization. 3rd Edition, Macmillan Publishing Co. Inc., New York.

[26] Dong, L. (2004) Perspective of Consumer Decision to Perceive Customer Service of B to C (E-Commerce). Journal of Intelligence, 8, 27-28.

[27] Haubl, G. and Trifts, V. (2000) Consumer Decision Making in Online Shopping Environments: The Effects of Interactive Decision Aids. Marketing Science, 19, 4-21.

[28] Chen, S. (2005) Marketing Psychology. Jinan University Press, Guangzhou.

[29] Wu, C.S. and Cheng, F.F. (2011) The Joint Effect of Framing and Anchoring on Internet Buyers’ Decision-Making. Electronic Commerce Research and Applications, 10, 358-368. http://dx.doi.org/10.1016/j.elerap.2011.01.002

[30] Xu, P. (2001) Consuming Psychology Study. Shanghai University of Finance \& Economic Express Co. Ltd., Shanghai.

[31] Zhou, Y.L. (2010) The Study of Network Consumer Decision and Application. Shandong University, Jinan.

[32] Engel, J.F., Kollat, D.T. and Blackwell, R.D. (1968) Consumer Behavior. Holt, Rinehart \&Winston, New York.

[33] Kotler, P. (1995) Marketing Management Analysis, Planning Implementation and Control. Prentice-Hall, Englewood Cliff.

[34] Ke, Q. (2004) The Research on E-Consumer Buying Behavior Model. Central China Normal University, Wuhan.

[35] Li, S.S., Chen, Y.W. and Li, J.Y. (2006) Shopping Decision-Making Model: An analysis of Consumer Online. Advances in Psychological Science, 14, 294-299.

[36] Hawkins, D.J., Best, R.J. and Coney, K.A. (2003) Consumer Behavior: Building Marketing Strategy. 8th Edition, Machine Industry Press, Beijing, 475-479.

[37] Yang, C.Y. (2007) The Difficult Choice: Research on Choice of Consumer Based on Psychology. Modern Economic Research, 3, 71-74.

[38] Zhou, F.W. and He, H. (2010) The Choice of Framing Effect-The Influence of Circumstance for Choice of Consumer. Productivity Research, 9, 99-100.

[39] Levin, L.P., Schneider, S.L. and Gaeth, G.J. (1998) All Frames Are Not Created Equal: A Typology and Critical Analysis of Framing Effects. Organizational Behavior and Human Decision Processes, 76, 149-188.

http://dx.doi.org/10.1006/obhd.1998.2804 
[40] Mou, B.B. and Si, J.W. (2012) The Influence of Promotion Strategy and Need for Cognitive Closure on Ambiguity Consumption Decision Making. Psychological Research, 3, 61-69.

[41] Li, S.L. and Jing, F.J. (2014) The Effects of Utilitarian and Hedonic Attribute on Price Frame in Bundling. Commercial Research, 442, 105-112.

[42] Schindler, R.M., Maureen, M. and Nada, N.B. (2005) Shipping Charges Skepticism: Implications for Direct Marketers Pricing Formats. Journal of Interactive Marketing, 19, 41-53. http://dx.doi.org/10.1002/dir.20030

[43] Cheng, Y.R. (2013) The Effect of Need for Cognition and Framing Effect on College Students' Purchase Decisions: An Empirical Research. Southwest University, Chongqing.

[44] Liang, H.H. (2009) The Impact of Decision Goal and Cognition Needs on Sunk Cost Effect. Henan University, Zhengzhou. 
Scientific Research Publishing (SCIRP) is one of the largest Open Access journal publishers. It is currently publishing more than 200 open access, online, peer-reviewed journals covering a wide range of academic disciplines. SCIRP serves the worldwide academic communities and contributes to the progress and application of science with its publication.

Other selected journals from SCIRP are listed as below. Submit your manuscript to us via either submit@scirp.org or Online Submission Portal.
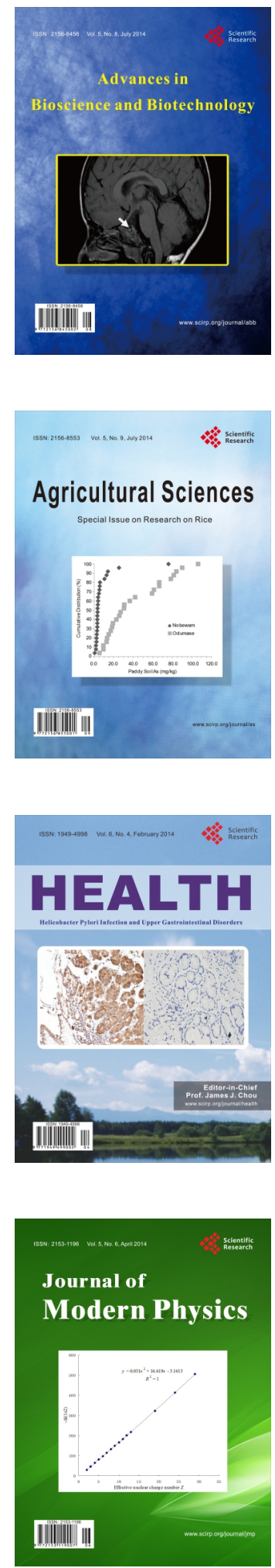
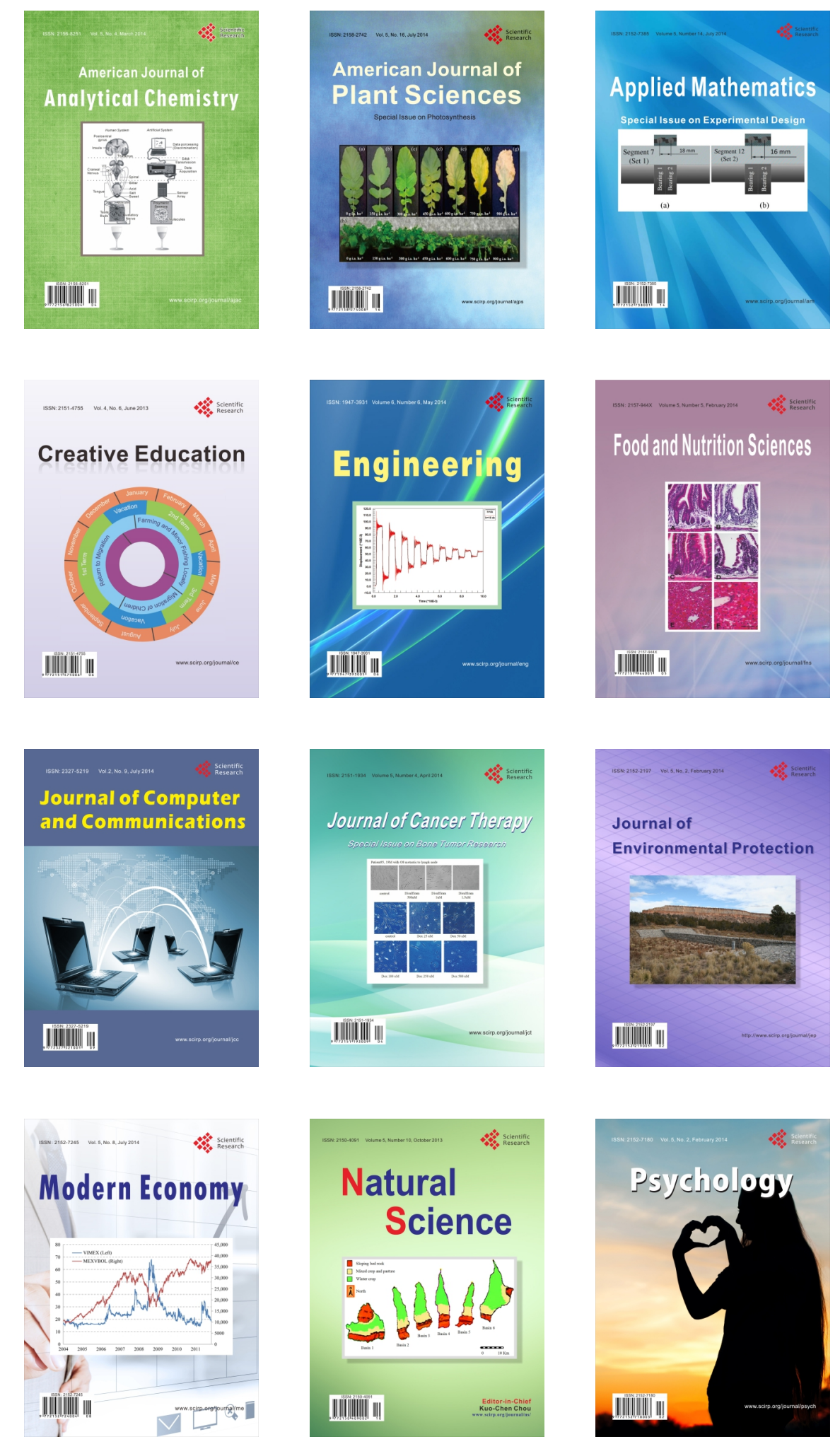